\title{
PHOTO-MODELING AND CLOUD COMPUTING. APPLICATIONS IN THE SURVEY OF LATE GOTHIC ARCHITECTURAL ELEMENTS
}

\author{
P. Casu ${ }^{a}$, C.Pisu ${ }^{\text {a }}$ \\ ${ }^{a}$ D.I.C.A.A.R., Department of Civil, Environmental Engineering and Architecture, Cagliari University, 09124 Cagliari, \\ Italy - paolacasu@gmail.com, claudiapisu@gmail.com
}

KEY WORDS: Photo-Modeling, Cloud Computing, Late Gothic Architecture, Geometrical analysis.

\begin{abstract}
This work proposes the application of the latest methods of photo-modeling to the study of Gothic architecture in Sardinia. The aim is to consider the versatility and ease of use of such documentation tools in order to study architecture and its ornamental details. The paper illustrates a procedure of integrated survey and restitution, with the purpose to obtain an accurate 3D model of some gothic portals. We combined the contact survey and the photographic survey oriented to the photo-modelling. The software used is $123 \mathrm{D}$ Catch by Autodesk an Image Based Modelling (IBM) system available free. It is a web-based application that requires a few simple steps to produce a mesh from a set of not oriented photos. We tested the application on four portals, working at different scale of detail: at first the whole portal and then the different architectural elements that composed it. We were able to model all the elements and to quickly extrapolate simple sections, in order to make a comparison between the moldings, highlighting similarities and differences. Working in different sites at different scale of detail, have allowed us to test the procedure under different conditions of exposure, sunshine, accessibility, degradation of surface, type of material, and with different equipment and operators, showing if the final result could be affected by these factors. We tested a procedure, articulated in a few repeatable steps, that can be applied, with the right corrections and adaptations, to similar cases and/or larger or smaller elements.
\end{abstract}

\section{INTRODUCTION}

The study and understanding of architecture occurs through the architectural survey and the resulting graphical summary of what has been observed, measured and examined. Measuring an architecture means performing an operation that will lead to a full understanding of the work in its entirety and in its details, capturing the dimensional and constructive values, but also formal and cultural ones. The study contained in this communication is inspired by the need to deepen the knowledge of some detailed aspects of the late-Gothic buildings of Sardinia.

The architectures of Sardinia, built between the XV and XVII centuries, are part of the Mediterranean Gothic (Mira \& Zaragoza Catalán, 2003), and can be placed in the vein of the Spanish late Gothic (Segni Pulvirenti \& Sari, 1994). These architectures are still largely unknown, especially those located in minor contexts.

This study aims to deepen the knowledge about the ornamental details of these architectures through the application of the latest methods of photo-modelling, in order to consider the versatility and ease of use of such documentation tools. We propose a procedure of integrated survey and restitution that will lead to geometric analysis applied to the specific case of gothic portals sited in the centre and in the south of the island, in order to make a comparison between the different decorative and compositional choices followed by manufacturers in the creation of these openings.

We combined the contact survey and the photographic survey oriented to the photo-modelling. This choice allowed us to integrate the classical measurements with the photo-modelling. Through this method we were able to model all the elements and to quickly extrapolate simple sections. In the first phase we executed preparatory sketches with the annotation of measures, and we brought back the elements detected in simple geometric shapes in order to study the dimensions. In the second phase we studied more deeply decorations through the photo-modelling construction of the 3D model.

We carefully evaluated the operations to be performed on-site in relation with the photo-modelling process. The software used is 123D Catch by Autodesk an Image Based Modelling (IBM) system available free. It combines an app and a web-service. It produces a model from a sequence of photos taken in a very simple way and returns a mesh which must be oriented and scaled in the virtual space. Although the photographic survey is influenced by light and by the conditions of photo taking, it is very versatile, in fact, allows to combine multiple processing, also performed at different times.

The use of photo-modelling systems like this has seen wide application especially in the documentation of archaeology (Poehler \& Ellis, 2011) and historical buildings.

The accuracy of the Image Based Modeling process was compared with similar measurements using laser scanner highlighting the strengths and limitations of the method that is most suitable in the study of contained size elements. (Fratus de Balestrini \& Guerra 2011).

About Autodesk 123D Catch, Kersten et al. (2012) present practical investigations by comparing results from the software package Bundler/PMVS2 (an open-source software of the University of Washington) and the Autodesk Web service Photofly/123D Catch Beta with results from terrestrial laser scanning. It was stated that the geometrical differences are not very large between image- and distance-based systems. However, it could also be concluded that the image-based systems had problems with large objects such as buildings to obtain geometrically correct results. Visual attractive 3D models could be obtained with the Autodesk Web service, if the objects are not very large and show rotund forms. (Kersten \& Stallman 2012)

The Autodesk 123D Catch software used in this work operates in cloud computing for the computation of correspondences between the images and the creation of triangulated mesh. The software also creates the texture of the mesh using the 
referenced photos. In post-production operations, before exporting the mesh to another software that manages and models it, we traced over the model a network of defined points and lines using the tools provided by the software. These points are chosen in correspondence with the real ones used during the recording of the reference measurements. The app also permit a definition of a coordinate system using the traced points to orient the mesh. If necessary, a large number of other points can be placed, in correspondence, for example, of the junctions between the ashlars, so as to specify the coordinates of each element of the building.

There are many software that operate in the same way and the current literature contains numerous examples of comparison of the results obtained with these procedures. (Gherardi et al. 2011) (Pierrot Desilligny \& Clery, 2011). We chose Autodesk 123D Catch because it offers a simple interface.

The work, done through the use of these modern technologies, provides a way to study historic architecture. Starting from the survey of the studied element we obtain a detailed 3D model that leads to a full understanding of shape and proportions of the object. The proposed method is simple and rapid and has therefore allowed the accurate documentation of some portals.

Moreover, we encoded the methodology of survey so the results obtained are objectively comparable. We tested the application on a specific case and performed a comparison between various architectural elements, in particular between sections of the mouldings, highlighting similarities and differences, that with other systems, would be long and laborious to obtain.

\section{OBJECT OF STUDY}

In Sardinia the late Gothic constructive types reached the maximum spread between the XV and XVII centuries. During this period, groups of local manufacturers reworked, according to their taste, shapes acquired from Spain, particularly from Catalonia. Portals, along with the vaults and the rose windows, are certainly the strongest characteristic features of religious buildings in Sardinia. Notable examples of these elements are found throughout the island. In the following work we consider the portals with pointed arch, the most common and most representative late Gothic openings which are more common in the south and center of the island.

We choose some portals of churches in the districts of Cagliari and Oristano: the church of La Speranza (second half of the XV century) in Cagliari in the neighborhood of Castello; San Pietro in Assemini (Ca) (first half of the XVI century); Sant'Ambrogio in Montserrato (Ca) (second half of the XVI century); the church of Santo Spirito (the first half of the XVI century) sited in Allai (Or).

We selected portals that have similar structural characteristics albeit with some differences related to the material and the state of conservation. Those in the district of Cagliari are made in limestone of Cagliari, while that of Allai is in calc-alkaline volcanic rock. There is a wide variety of shapes and decorations. Portals with pointed arches, ultimately, are all different from each other, but there are some common rules that can be shown and provide a distinct criterion of reading (Casu \& Pisu, 2010). We found some differences both in the proportions of various elements, and in the use of moldings and ornaments, but the constituent parts are always the same. The opening is a rectangular shape bounded at the sides by molded piers, which rest on truncated cone shape bases, and finish in capitals of variously decorated cylindrical shape.

The pointed arch is set on the top of the capitals. The arch is composed of molded voussoirs and surmounted by an eyebrow arch ending in two corbels entirely similar to the capitals in shape and type, but of larger dimensions.

With exception of the portal of Allai, the opening is defined by a lintel surmounted by a string course. This intersects the arch immediately above the capitals. In the portals of Assemini and Cagliari there are side shelves as additional decoration of the lintel.

Among the portals with these characteristics, we noticed some differences, for example, the number of bands in the molding. In order to test the method all the selected portals have tripartite molding.
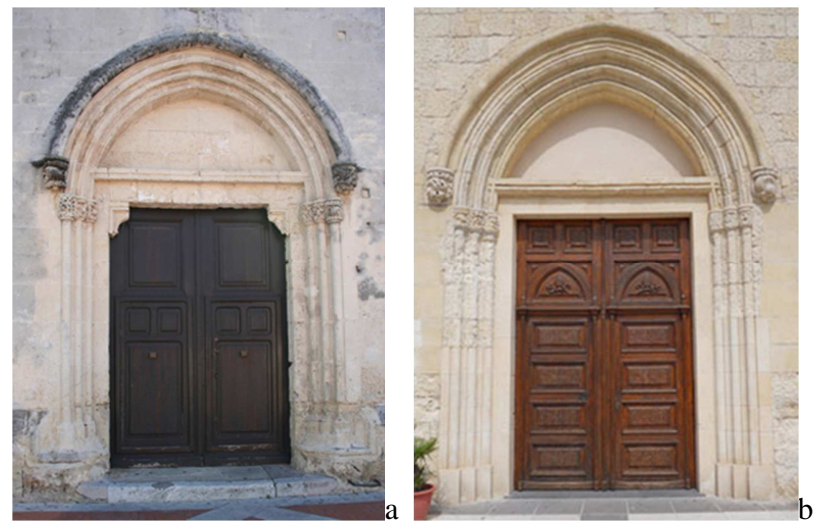

Figure 1. Studied portals: Monserrato, Sant' Ambrogio
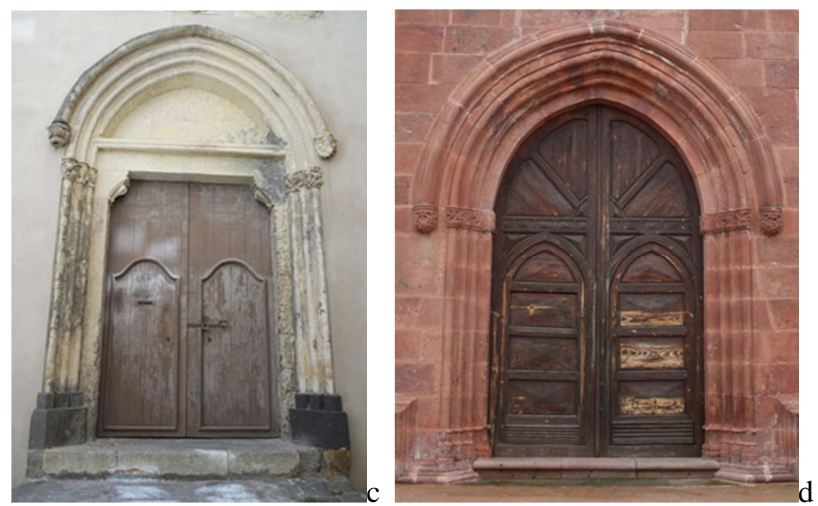

Figure 2. Studied portals: c) Cagliari, La Speranza; d) Allai, Santo Spirito

\section{METHOD}

\subsection{Survey and restitution process}

From time to time, the methodology evolves and adapts it to problems that exist in particular cases. At each survey, a new difficult, a new procedure, a new technology adds to the already encoded and consolidated methodologies. This way of working, which adds the interpretative operation, to the cognitive and documentary ones, elevates the purely technical survey to research activities. (Gurgone, Inglese, 2008)

In the field of architectural survey there isn't the better and decisive technique. There are several opportunities of choices and integrations of the different techniques. That choices are influenced by several factors including the experience, the type of object detected, the material, the purpose of the survey, the geometric detail required, the project budget, etc. (Vernizzi 2017), (Remondino 2011).

In the specific case we chose to use a method of integrated survey that combines direct survey and photographic survey 
oriented to the photo-modeling. The word "photo-modeling" refers to the process of transactions carried out in the digital domain. This process starting from raster images leads to the creation of a three-dimensional model. In recent years, such techniques have received a great success in the field of conservation and enhancement of cultural heritage and will emerge as one of the frontiers of passive detection. (Filippucci 2011)

This choice allowed us to integrate the classical measurements with the photo-modeling and to overcome the problems related to the direct survey of the moldings. Through the photomodeling we were able to model these elements and to quickly extrapolate simple sections of the 3D model.

In the first phase we executed preparatory sketches with the annotation of measures, and we schematized the elements to be measured, bringing them back to simple geometric shapes, in order to better study their dimensions. To determine the measures, we used simple tools for contact survey: meter, set square, telescopic poles and the laser distance meter (Docci \& Maestri, 2009). To complete the survey operations, we took a set of photo functional to photo-modeling software. We carefully evaluated the operations to be performed on-site in relation with the photo-modeling process. The software used to elaborate the photos is 123D Catch by Autodesk available free and that operate on the cloud. It produces mesh surfaces from a sequence of photos taken in a very simple way.

Ultimately the adopted survey procedure is articulated according to the following scheme:

- identification of buildings with significant features based on analysis of census data;

- execution of preparatory sketches;

- collection of measures strictly necessary and positioning of reference points on the area to be photographed in order to proceed to a correct orientation and scaling of the obtained model.

- $\quad$ execution of the photos;

- $\quad$ image processing using Autodesk 123D Catch software;

- processing of the resulting mesh and extrapolation of significant sections for the construction of the 3D model, with other software;

- creating sections and analysis of results.

\subsection{Image Based Modeling and Cloud Computing}

123D Catch is a free software released by Autodesk and is the evolution of the previous Autodesk Photofly. It is a web-based application that requires a few simple steps to produce a mesh from a set of not oriented photos.

This system as similar, Bundler (Snavely et al. 2008), Patchbased Multi-View Stereo-Version 2 (PMVS2) (Furukawa 2010), and ARC 3D Webservice (Vergauwen \& Van Gool, 2006), adopt computer visual techniques to reconstruct $3 \mathrm{D}$ models without requiring photogrammetry information, such as interior and exterior orientations (Yang et. al. 2012).

The software is based on process that obtains the surface using the SfM (Structure from Motion) technique. The main principle of the SfM is to establish the relationship between the different images by analyzing the relative and absolute positions of the field image (Yang et. al. 2012). The software, developed for modeling objects of any size, has been generally used to document something taking pictures along a ring in the center of which there is the element to be modeled. For this reason, the phase of collecting images is very important, because the entire project depends on it . The best results are obtained when it is possible to move around the object. In this way photos can be taken at an angle of about $10-15^{\circ}$ between shots. The result is a set of pictures which covers the object from many different angles. The overlap between the different photos is sufficient to recognize all parts of the object.

A good general guideline is the Rule of 3: every part of the scene you want to reconstruct should be visible on at least 3 photos. In a way, all the photogrammetric software work like the laser scanner: whatever is not directly visible in at least 2 of 3 photos will result in a gap of information (which may anyway be interpolated by the software, but it will be far from being as accurate as the general scene). Almost all the photogrammetric software nowadays available are based on the Structure from Motion principles. For this reason, the best reconstructions come from at least a triplet of photos. (Cantoro, 2012)

In addition, reflections and very marked shadows should be avoided photographing objects exposed to direct sunlight. Blurry images or noisy images, due to motion blur or out-offocus, should be discarded. It is also preferable to use the same camera with the same focal length and the same resolution for all shots. Although the photographic survey is influenced by light and by the conditions of photo taking, however is very versatile, in fact, allows to combine multiple processing, also performed at different times.

The Autodesk 123D Catch software used in this work operates in cloud computing. It calculates the correspondences between the images and creates a triangulated mesh. According to the NIST definition "Cloud computing is a model for enabling ubiquitous, convenient, on-demand network access to a shared pool of configurable computing resources (e.g., networks, servers, storage, applications, and services) that can be rapidly provisioned and released with minimal management effort or service provider interaction. This cloud model is composed of five essential characteristics, three service models, and four deployment models." (NIST, 2011). The service models of 123D Catch is the Software as a Service (SaaS) model. In this type of service the capability provided to the consumer is to use the provider's applications running on a cloud infrastructure. The applications are accessible from various client devices, but the consumer does not manage or control the underlying cloud infrastructure.

Due to the characteristic of SaaS the user can't control the process of drawing up the mesh. However, some processing operation are allowed. The application automatically returns the textured mesh of the surface and allows to calculate it according to three different degrees of definition. The application also provides drawing tools that allow you to draw points and lines. These can be used for:

- $\quad$ orient the reference system;

- identify particular elements of the measured object;

- build a grid of points and lines which schematize the object.

These points can be drawn in correspondence with the real ones, which identify the reference measurements on the object. The grid of points and lines can be exported in .DWG and used for other processing.

The limitation of this software, as well as all of this kind, is the uncertainty of the measurements. It gives a mesh which must be oriented and scaled in the virtual space, in order to obtain a usable model from the photographic images.

The product obtained is a mesh that can be exported in .OBJ format. It can be elaborated with 3D modeling software that can import this kind of format. In the specific case we used Autodesk 3ds Max.

Ultimately, the steps to be taken to obtain the mesh are:

- to create an Autodesk account that allows the user to download the application and then access the web-service for processing; 
- to install the application 123D Catch and log in to the webservice to create the project;

- to choose the set of images and upload them to the server (doing this you choose to make them available to the provider of the server);

- to wait for the processing of the mesh by selecting the desired resolution from the three possible options;

- $\quad$ to download the processing product, and possibly to refine it by removing unnecessary parts and then to orient it;

- to export the oriented mesh, complete with textures, in .OBJ for the subsequent management in a 3D modeling software

\section{APPLICATIONS TO THE SPECIFIC CASE}

We tested the application on the portals, working at different scale of detail: at first the whole portal and then the different architectural elements that composed it. In particular, we performed a comparison between sections of the moldings, highlighting similarities and differences.

Portals previously described are disseminated in large part of the island, in particular in areas of the south and the center. Among these we have identified portals similar in shape, dating, condition and type of decorations. The collection of the direct measurements (contact survey) was smooth in all cases because the portals are not particularly large: the highest is Sant'Ambrogio, 6,073 m. We collected the data strictly necessary to determine the geometry and to scale the model obtained by the photo modeling software. Also the collection of photographic images was not difficult.

We took two sets of pictures for each portal using two different cameras. This operation was conducted to understand how the camera parameters and picture resolution could influence the final outcome. The cameras used are: Canon EOS 350D (camera1) and Casio EX-H15 (camera2). In addition, the photos were taken by two different operators. In this way we were able to make a comparison between two completely different elaborations. We done this work for all the portals. Here, we will show the obtained results about the Church of La Speranza in Cagliari (fig.4). It is located in an alley and the space for taking photo is reduced. We were forced to place the camera tilted with respect to the façade. This problem does not occur for the other three portals, that are situated in front of large spaces such as squares and plazas.

The preliminary inspection of the sites has allowed us to determine the best hour for taking photo. The moment was chosen according to the orientation of the portals. We selected the hour in which lighting looked better, and there were not accentuated shadows on the façades.

\begin{tabular}{|l|l|l|}
\hline & Camera1 & Camera2 \\
\hline Picture resolution & $2304 \times 3456$ & $3240 \times 4320$ \\
\hline Camera & $\begin{array}{l}\text { Canon EOS } \\
350 \mathrm{D}\end{array}$ & Casio EX-H115 \\
\hline F-stop & $\mathrm{f} / 5.6$ & $\mathrm{f} / 3.2$ \\
\hline Expositon time & $1 / 80 \mathrm{sec}$. & $1 / 60 \mathrm{sec}$ \\
\hline ISO & ISO-400 & ISO-64 \\
\hline Focal Distance & $18 \mathrm{~mm}$ & $4 \mathrm{~mm}$ \\
\hline Focal lenght & 35 & 24 \\
\hline
\end{tabular}

Tab.1 Technical characteristics of the used cameras

Eight photos were taken with the Camera1 and ten photos with the Camera2. We created a 123D Catch project for each set of photos. The software produced two mesh of the portal, one for each set of photos.

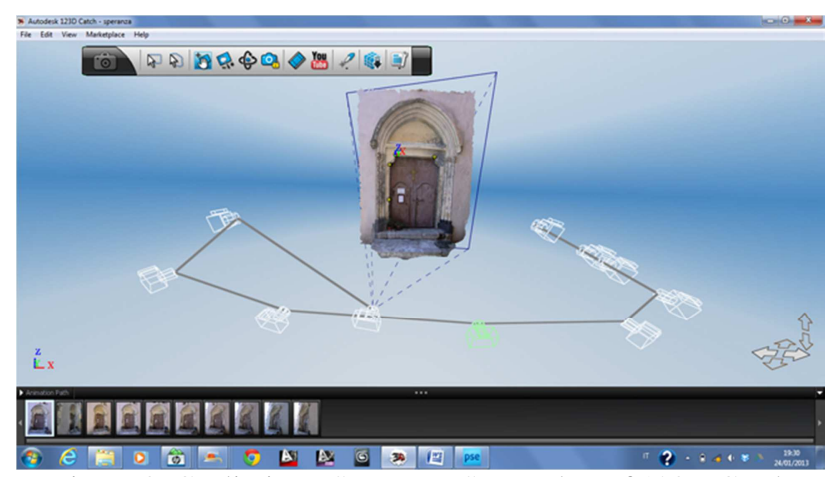

Figure 3. Cagliari, La Speranza. Screenshot of 123D Catch

The total time, necessary to obtain the product of the combination of the photos, depends on the speed of connection available. The connection rate determines, in fact, the loading time of images. The processing time depends, however, on the number and resolution of the photos used for the project. In the examined case, the shorter processing time were obtained with the set of photos of camera1, owing to both the smaller number of photos that compose it, and the lower resolution of them. The comparison between the models obtained by the software with the two sets of photos is shown in figure 4 . For the same reason, the mesh produced by the photo set of cameral is less dense than that produced by the photo set of camera2. Figure 5 shows the difference between the mesh of model1 and model2. At low resolution model1 have 35234 faces and model 270248 faces.
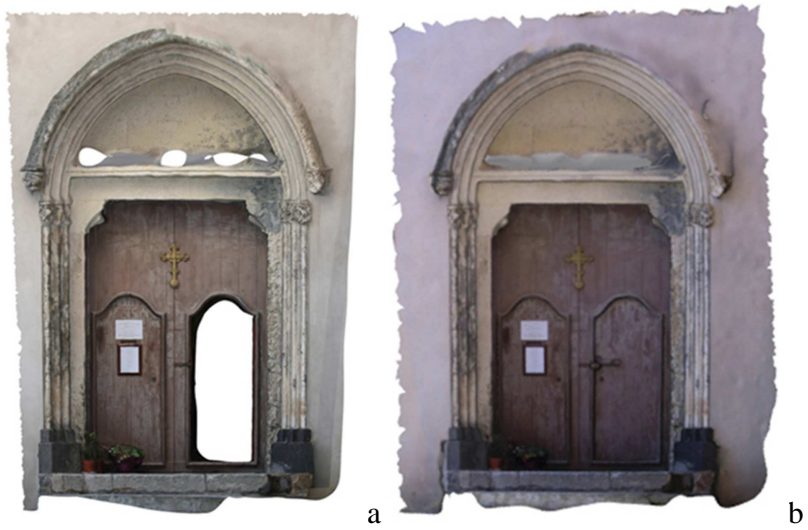

Figure 4. Portal of La Speranza, Cagliari. Result of processing of photo sets obtained with two different cameras: a) model1, Canon EOS 350D; b) model2, Casio EX-H15

We noticed that the two solutions give different results in the elaboration of areas of uncertainty. Modell shows holes in the area above the lintel and a lack of definition in the upper part of the right eyebrow. In model 2 the holes of the mesh are not present but above the lintel there are, however, areas in which the texture is not defined; also, the part of the eyebrow appears more approximate.

In some cases the mesh produced may have gaps or holes. The causes may be: some parts are not visible in a sufficient number of photos; the definition of photos does not guarantee, in that area, the required density of the mesh. In the considered case, the areas not covered by mesh, or those without texture, are above the capitals and lintel. The cause is that photos were taken below the capitals.

Figure 6 compares the horizontal section of the 3D model of the portal in the two cases. This test revealed that, at this scale, the type and quality of two cameras does not influence much the final result. 


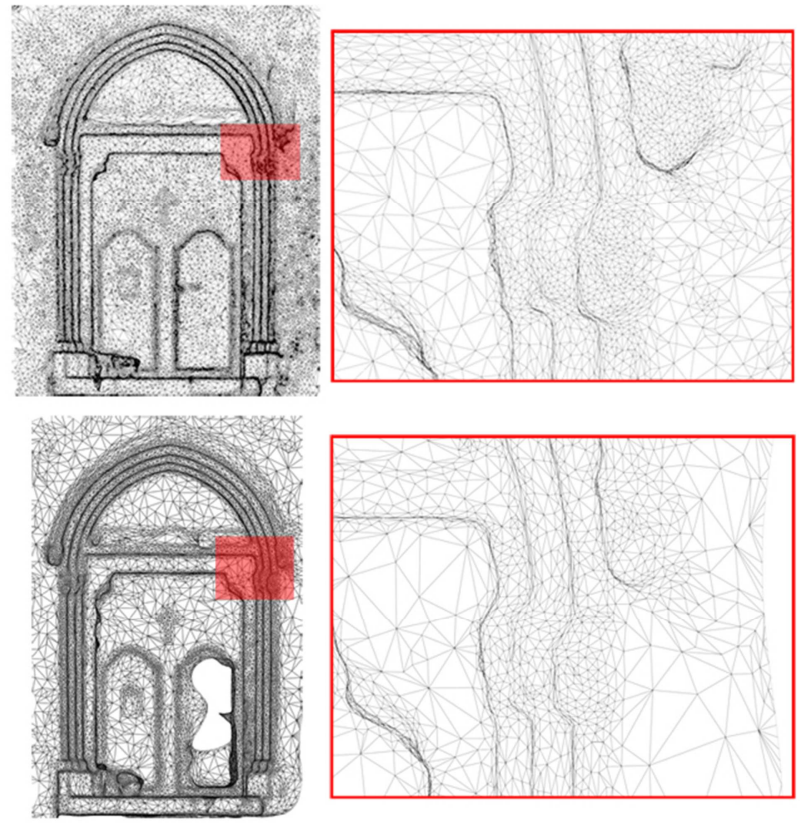

Figure 5. Comparison of the mesh obtained with two different cameras: a) model1, Canon EOS 350D; b) model2, Casio EXH15

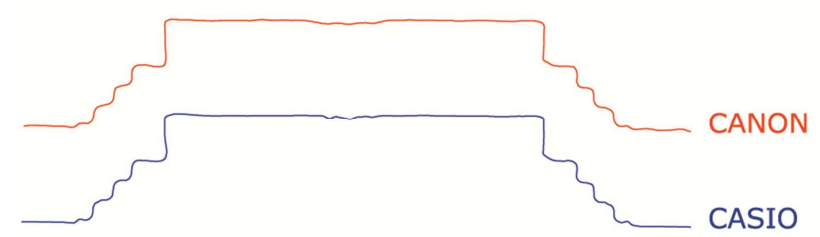

Figure 6. Comparison of the horizontal section obtained with two different cameras: a) model1, Canon EOS 350D; b) model2, Casio EX-H15

To get an accurate model of the moldings we needed more detail. Therefore, for the determination of the profiles of the moldings of each portal, we took a set of close-ups, distinguishing pier, base and capital. For each part were taken 10 photos on average.

Examining the calculations obtained we found that the model obtained from the detail photos, allows to appreciate the discontinuity on the surface of the stone caused by surface degradation, but the overall shape of the molding can be also extrapolated from less accurate photos.

Figure 7 shows the progressive increase of the pieces of the mesh in the three possible solutions offered by the application. Instead, Figure 8 illustrates the progressive increase of detail in the section obtained from the three different models. In this way the model can reach very high accuracy that allows a very faithful reproduction of details.

To get the sections, we used $3 \mathrm{ds}$ Max that, with simple steps, imports the .OBJ file, cuts the 3D model and produces the final rendered images. The obtained sections were imported as polylines in a CAD program that allowed us to get to the final plane representation of the profiles and their geometric simplification. The way to cut the mesh is similar to that usually adopted to obtain section from a point cloud produced by a laser scanner (Galizia \& Santagati, 2012).

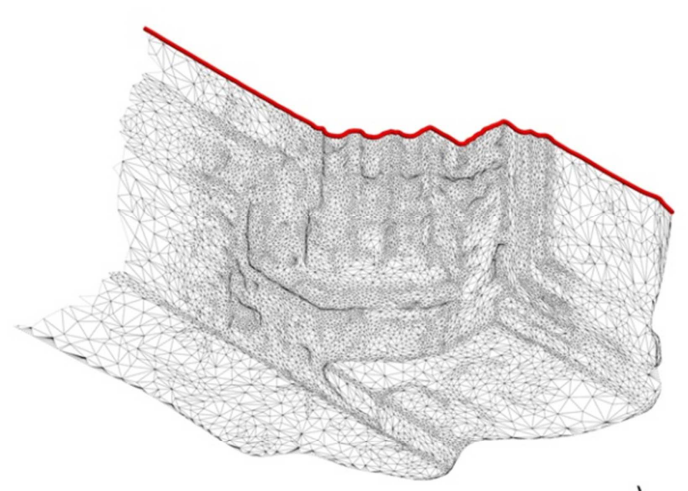

a)

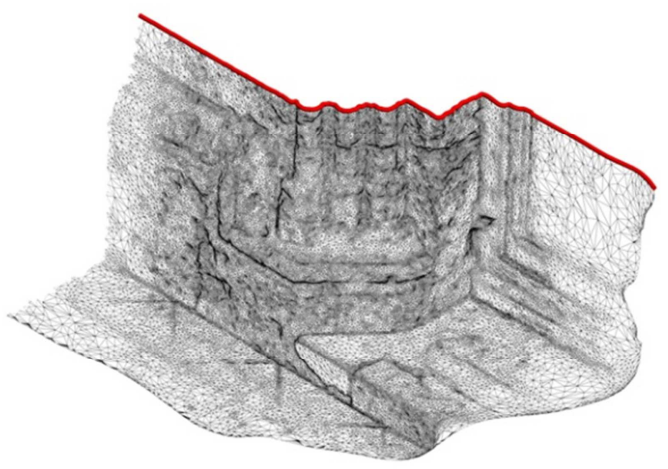

b)

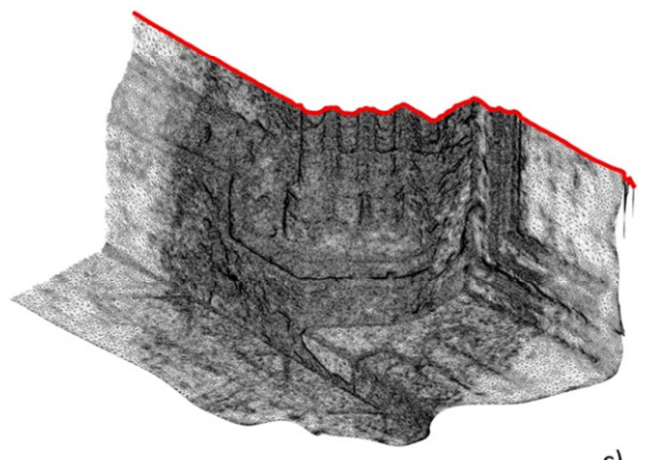

c)

Figure 7. Assemini, progressive increase in the density of the mesh: Low 24506 faces, Medium 111126 faces, High 526628 faces

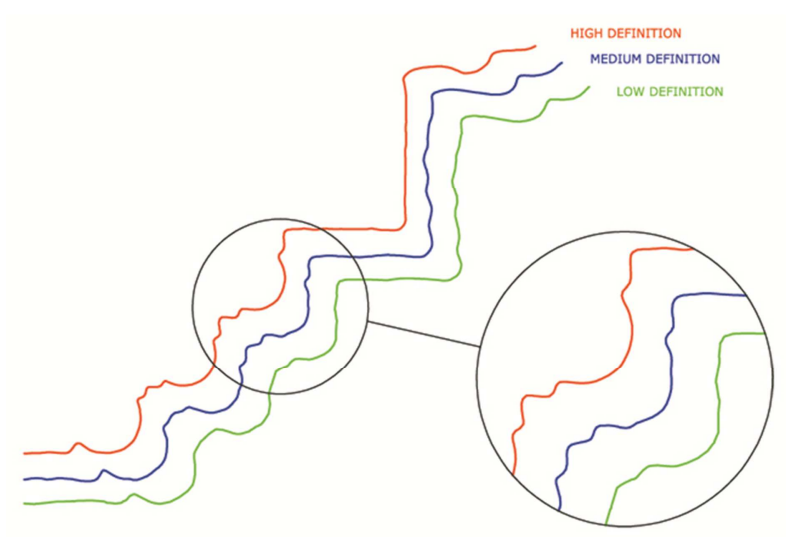

Figure 8. Assemini, San Pietro. Comparison between profiles of moldings obtained by sectioning the three mesh: High, Medium, Low 


\section{RESULTS}

The most important result of the applied method is to obtain a detailed model constituted by surfaces that already contain within themselves all the characteristics of the represented object. This result is obtained through a procedure consisting of a few steps easily repeatable.

The method has been applied to the entire portal as well as to some elements belonging to it. Moving from one scale of representation to another does not involve any change in the procedure, since it depends only on how photographic images should be taken. So with the same agility, you can model a part of a building, such as a detail.

An adequate inspection is necessary to ensure that the space in front of the object is sufficient for taking pictures, that there are no obstacles such as objects that obscure some parts, or other problems as exposure or lighting.

Therefore, the problems of survey, which in the case of direct measurement are various (Marino, 1990), in this way, are reduced to those related to photography.

When you project a survey of an object, in particular in architecture field, it is important to determine in advance some fundamental aspects that enable you to make informed choices both in terms of procedures and instruments to be taken, in order to save time and money without sacrificing quality in the results (Di Paola, 2010). So, choose the right procedure is closely related to the aim of the final work.

In the case stud, we assumed that the purpose of the model was to determine the original form of the object. This form would be submitted to a subsequent geometrical study to make a comparison. For this reason, the procedure has been calibrated according to the pursuit of this result.

We drew up a balance sheet between the obstacles to be overcome and the benefits obtained, and surely this was positive. Analyzing step by step the process we unequivocally concluded that is extremely valid.

\section{Advantages of the procedure}

- Stage of data collection:

1. Use of a few instruments

2.

3. Minimum time in gathering information.

4. Possibility to perform all the operations of collecting information by only one operator.

5. Minimum costs for the equipment: camera, laser distance meter, meter, pad of paper and pencil.

- $\quad$ Stage of processing the data:

1. Obtaining a mesh model complete with texture and manageable with standard 3D modeling software;

2. Limited number of operations to be performed with other software.

3. Quality of results (linked to the quality of the photos).

4. Minimal operator skills in the use of software.

5. Saving memory space on your pc, since the image processing occurs on the cloud.

6. Possibility to perform other tasks while the software works alone, it will alert us by email at the end of the process.

- Results:

1. Quality of the model.

2. Versatility of the model.

3. Accuracy of texture.

\section{Limits of the procedure}

- Stage of data collection:

1. Need to take some control measure.
2. Accessibility of the object to be documented. (need for auxiliary equipment for taking photos of items placed at a height high).

- $\quad$ Stage of processing the data:

1. 123D Catch works only if connected to a network. The limits of such characteristic are obviously tied to the speed of the network.

2. By agreeing to use the web-service you agree to share data relating to the draft prepared with the manager (especially photos).

- Result:

1. The process returns only surfaces and not volumes.

2. The mesh density may be very high and, for the management of the model, we would need a suitable hardware.

\section{CONCLUSIONS}

Ultimately the procedure has allowed us to obtain the flat section of the moldings. Also the comparison of the sections of the moldings (Figures 9-12) shows how the same solution of pilasters separated by fillets, adopted in the creation of the four portals, is open to different variations in size.

The application of the method has also graphically highlighted the state of degradation of the different moldings investigated. This degradation is closely linked to the type of material in which are carved moldings and its exposure to weathering. Particularly in the case of Cagliari and Monserrato, the edges forming the alternation between torus and fillets is almost imperceptible. Anyway, the sections obtained from the mesh reproduce in a precise and accurate way the present conformation of the molding, hardly documentable with direct survey. The obtained results are the basis for the graphic reconstruction of the original shape of the molding. Therefore this result will enable further study on the geometry and shapes, not only of the moldings of the pier, but of the whole decorative apparatus of the portal object of study.

Then we can conclude that the method is very effective, considering the margin of error, setting time and image processing, the necessary tools and minimal obstacles to overcome. Different sites have allowed us to test the procedure under different conditions of exposure, sunshine, accessibility, degradation of surface, type of material, and with different equipment and operators, showing that the final result is not significantly affected by these factors. This leads us to conclude that this procedure, articulated in a few repeatable steps, can be applied, with the right corrections and adaptations, to similar cases and/or larger or smaller elements.

\section{REFERENCES}

Cantoro, G. 2012, "Photogrammetric 3D restitution of surfaces using free tools", www.archaeolandscapes.eu/index.php/capture/aerialphotography/218.html (30 Jan. 2013)

Casu, P., Pisu, C., 2010. Rilievo e analisi geometrica dei portali del Campidano di Cagliari. APEGA 2010, X Congreso International de Expresión Gráfica aplicada al Edificatión, Libro de Actas, Universidad de Alicante Departemento de Expresión Gráfica y Cartografía, Editorial Marfil, Alicante 2010, pp.825-834 


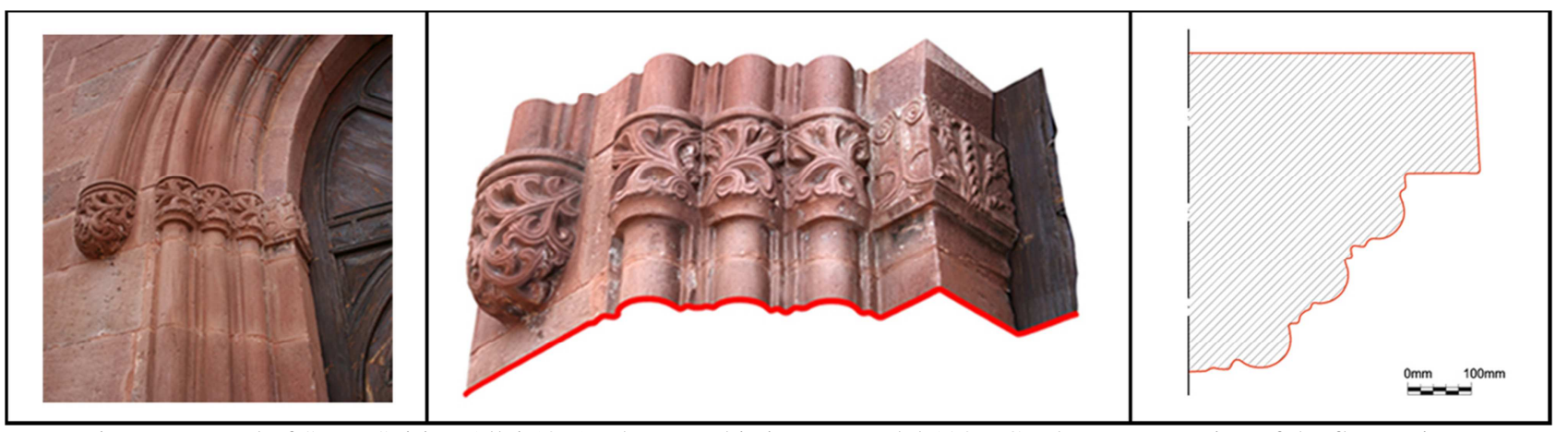

Figure 9. Portal of Santo Spirito, Allai (OR): photographic image; model 123D Catch; reconstruction of the flat section.

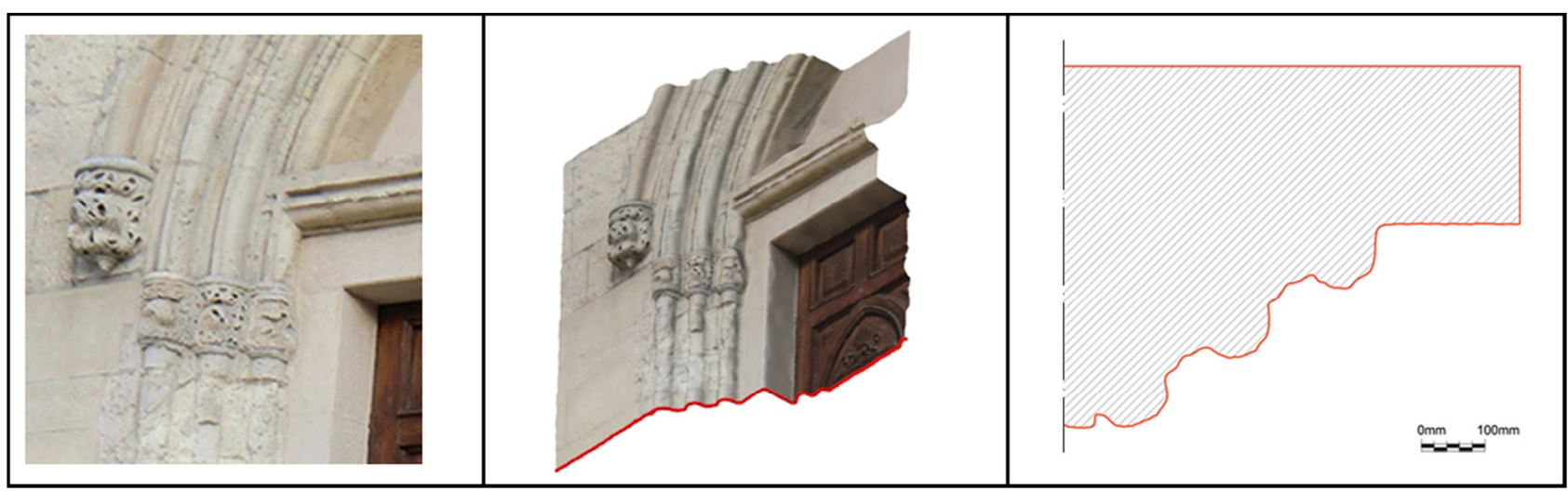

Figure 10. Portal of Sant'Ambrogio, Monserrato (Ca): photographic image; model 123D Catch; reconstruction of the flat section.

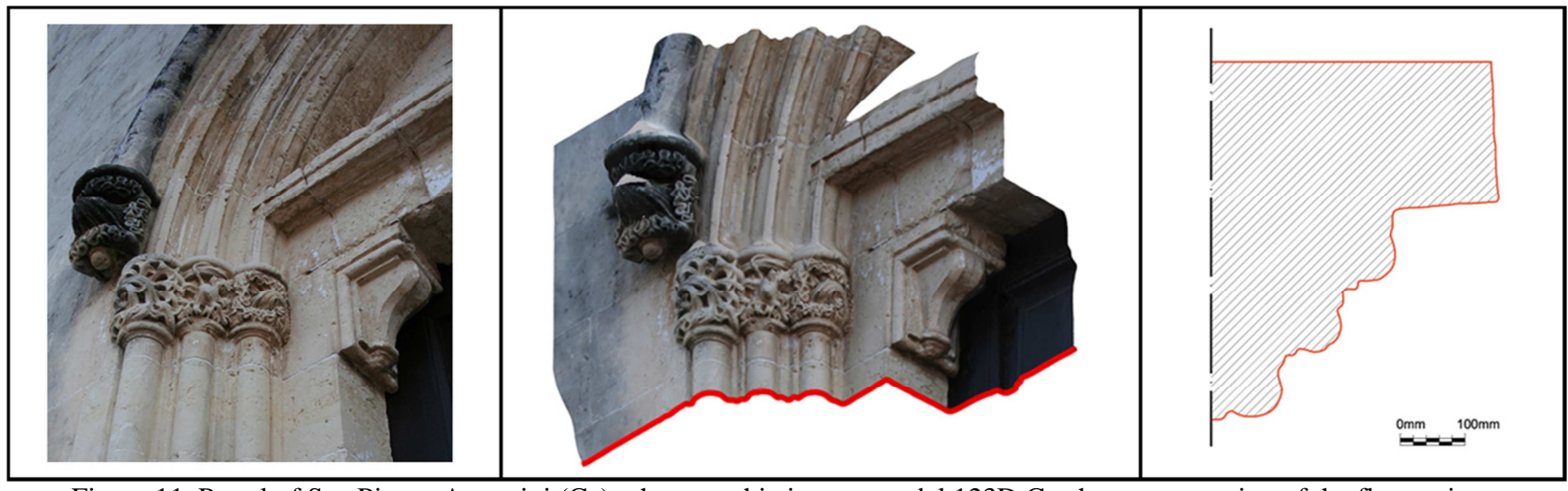

Figure 11. Portal of San Pietro, Assemini (Ca): photographic image; model 123D Catch; reconstruction of the flat section.

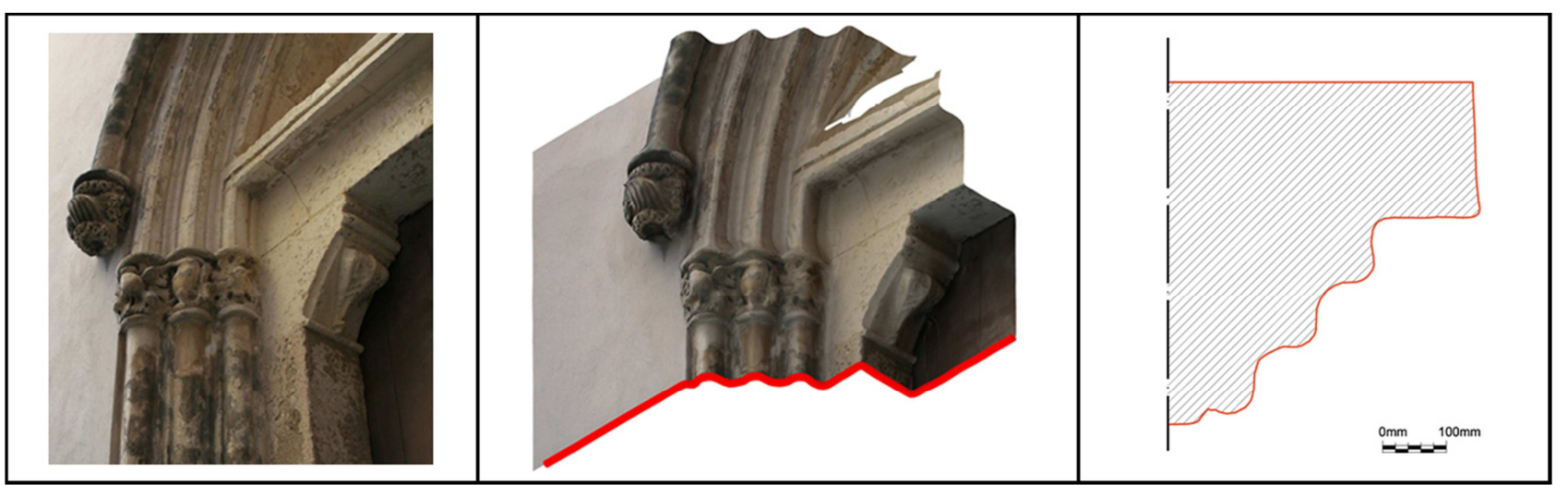

Figure 12. Portal of La Speranza, Cagliari: photographic image; model 123D Catch; reconstruction of the flat section. 
Docci, M., Maestri, D., 2009, Manuale di rilevamento architettonico e urbano. Nuova edizione ampliata, Laterza, Roma.

Gherardi, R., Toldo, R., Garro, V., Fusiello, A., 2011 Automatic camera orientation and structure recovery with Samantha. The International Archives of the Photogrammetry, Remote Sensing and Spatial Information Sciences, XXXVIII5/W16, 261-268.

Gurgone, N., Inglese, C. 2008. Del discrimine tra scienza e tecnica. Il rilievo dei mosaici dell'Accademia di Scherma al Foro Italico. Disegnare idee immagini, 36, pp. 60-71.

De Luca, L., 2011. La fotomodellazione architettonica. Rilievo, modellazione, rappresentazione di edifici a partire da fotografie. Dario Flaccovio, Palermo.

Di Paola, F., 2010. Architecture scanned. Virtual model of a historical stratification, Atti dell'XIII Congreso International de Expresión gráfica arquitectónica, Editorial de la Universitat Politècnica de València, Departamento de Expresión Gráfica Arquitectónica, Escuela Técnica Superior de Arquitectura de Valencia, Universidad Politécnica de Valencia (Spain), pp. 161-165.

Filippucci, M., 2010. Nuvole di pixel. La fotomodellazione con software liberi per il rilievo d'architettura. Disegnarecon, 3, pp. $150-163$.

Fratus de Balestrini, E., Guerra, F., 2011. New instruments for survey: on line softwares for $3 \mathrm{~d}$ recontruction from images. The International Archives of the Photogrammetry, Remote Sensing and Spatial Information Sciences, XXXVIII-5/W16, pp. 545552.

Furukawa, Y., 2010. PMVS2, Department of Computer Science and Engineering, University of Washington, Seattle, Washington. http://grail.cs.washington.edu/software/pmvs/ (30 Jan. 2013)

Kersten, Th., Lindstaedt, M., Mechelke, K., Zobel, K., 2012. Automatische 3D-Objektrekonstruktion aus unstrukturierten digitalen Bilddaten für Anwendungen in Architektur, Denkmalpflege und Archäologie. Publikationen der Deutschen Gesellschaft für Photogrammetrie, Fernerkundung und Geoinformation, 21, pp. 137-148.

Kersten, T., Stallmann, D., 2012. Automatic texture mapping of architectural and archaeological $3 \mathrm{~d}$ models. The International Archives of the Photogrammetry, Remote Sensing and Spatial Information Sciences, XXXIX-B5, 273-278.

Marino, L., 1990. Il Rilievo Per Il Restauro. Hoepli, Milano.

Mira, E., Zaragozá Catalán, A., 2003. Una arquitectura gótica mediterránea, catálogo exposición, Generalitat Valenciana. Conselleria de Cultura i Educació. Subsecretaría de Promoció Cultural, Valencia.

Nguyen, H.M., Wünsche, B., Delmas, P., Lutteroth, C., n.d. 3D Models from the Black Box: Investigating the Current State of Image-Based Modeling. Advanced Computer Graphics: COMPSCI 715 Semester 2 (2012), City Campus.
NIST National Institute of Standards and Technology, U. S. Department of Commerce, The NIST Definition of Coud Computing, Special Publication 800-145, http://csrc.nist.gov/publications/nistpubs/800-145/SP800-

145.pdf (30 Jan. 2013)

Pierrot Deseilligny, M., Clery, I., 2011. APERO, an open source bundle adjusment software for automatic calibration and orientation of set of images, The International Archives of the Photogrammetry, Remote Sensing and Spatial Information Sciences, XXXVIII-5/W16, 269-276.

Poehler, E.E., Ellis, S.J.R., 2012. The 2011 Season of the Pompeii Quadriporticus Project: The Southern and Northern Sides. FOLD\&R FastiOnLine documents \& research, 249, pp. $1-12$.

Remondino, F., 2011. Rilievo e modellazione 3D di siti e architetture complesse. Disegnarecon, 4, pp. 90-98.

Remondino, F., El-Hakim, S., Girardi, S., Rizzi, A., Benedetti, S., Gonzo, L., 2009. 3D Virtual Reconstruction and Visualization of Complex Architectures-The" 3D-ARCH" Project, in: Proceedings of the ISPRS Working Group V/4 Workshop 3D-ARCH“ Virtual Reconstruction and Visualization of Complex Architectures", 2009.

Galizia, M., Santagati, C., 2012. Architettura e/è Geometria: dalla forma architettonica alla costruzione geometrica. Disegnarecon, 5, pp. 135-143

Segni Pulvirenti, F., Sari, A., 1994. Architettura tardogotica e d'influsso rinascimentale. Collana Storia dell'Arte in Sardegna, Ilisso, Nuoro.

Snavely, N., Seitz, S.M., Szeliski R., 2008, Modeling the World from Internet Photo Collections. International Journal of Computer Vision, 80(2), pp. 189-210

Vergauwen, M., Van Gool, L., 2006. Web-based 3D Reconstruction Service. Machine Vision and Applications 17, pp. 411-426.

Vernizzi, C., 2007. Considerazioni sul rilevamento per la valutazione strutturale di architettura storica monumentale: le volte della navata centrale del Duomo di Parma, Disegnare. Idee, Immagini. 35, pp. 74-85

Yang, M.-D., Chao, C.-F., Huang, K.-S., Lu, L.-Y., Chen, Y.-P., n.d. Image-based 3D scene reconstruction and exploration in augmented reality. Automation in Construction. In press. Corrected proof.

http://www.sciencedirect.com/science/article/pii/S09265805120 01690 (30 Jan. 2013)

Yuan-Fang, W., 2011. A Comparison study of five 3D Modelling Systems Based on the SfM Principles. 